\title{
Disposições temporais de futuro e longevidade escolar em famílias populares
}

\author{
Maria José Braga Viana*
}

\section{Resumo:}

Neste trabalho descrevo resultados de duas investigações que abordam uma problemática de fundo comum: as condições que possibilitam o fenômeno, estatisticamente improvável, da longevidade escolar em meios populares. Mais especificamente, busco identificar nas práticas socializadoras de famílias populares um espaço de constituição de disposições facilitadoras de longevidade escolar nesses meios. Defendo que esta seria uma das formas por meio das quais as famílias populares estariam presentes na escolarização prolongada de seus filhos. Dentre os tipos de disposições investigados destaco, para esse trabalho, as temporais. Em pesquisa mais recente estudei sete casos de estudantes do Curso de Pedagogia da FaE/UFMG dos anos de 2002 e 2003, via entrevistas; esses sujeitos foram selecionados no interior de um corpus de 120 autobiografias escolares produzidas de forma escrita. Embora focando os dados das entrevistas, a análise que aqui se desenvolve considera também elementos dessas autobiografias, assim como das trajetórias de dois casos de uma pesquisa anterior. Uma conclusão mais geral desses estudos: existe, nessas famílias, um horizonte de futuro distendido - disposição que é atípica para os meios populares -, expresso, sobretudo, na possibilidade de uma vida melhor para os filhos via escola.

Palavras-chave: Lar e escola. Escolaridade. Família.

* Doutora em Educação pela Universidade Federal de Minas Gerais (UFMG). Professora adjunta da Faculdade de Educação da UFMG, membro do núcleo de pesquisa Observatório Sociológico Família-Escola (OSFE). 


\begin{abstract}
"O futuro é uma coisa que cê tem que construir. Eu não acho que o futuro vai cair do céu pra mim, não! [...] Eu tenho que construir minha própria herança! [...] Eu tinha que correr atrás!.” (ANDRÉ, ${ }^{1}$ um dos jovens entrevistados).
\end{abstract}

\title{
Introdução
}

Nesse trabalho ${ }^{2}$ descrevo resultados de uma pesquisa que buscou compreender a relação entre práticas socializadoras de famílias populares e a constituição de disposições facilitadoras de longevidade escolar nesses meios - longevidade entendida como a permanência no sistema de ensino até a entrada no ensino superior (VIANA, 2006). ${ }^{3}$ Dentre os tipos de disposições investigados, destaco aquele ligado à relação com o tempo. Estudei sete casos de estudantes do Curso de Pedagogia da FaE/UFMG dos anos de 2002 e 2003, via entrevistas; esses casos foram extraídos de um corpus de 120 autobiografias escolares produzidas de forma escrita. Embora focando os dados das entrevistas, a análise que aqui se desenvolve considera também elementos dessas autobiografias.

Nessa investigação procurei identificar formas específicas de presença das famílias populares na escolarização dos filhos, focando as práticas socializadoras dessas últimas. Esse estudo representa, por sua vez, um desdobramento de pesquisa anterior (VIANA, 2007) que, noutro contexto, colocou as disposições temporais de futuro como um dos parâmetros centrais de análise. Essas duas investigações têm uma problemática de fundo comum: a compreensão de condições que possibilitam o fenômeno, estatisticamente improvável, da longevidade escolar em meios populares.

O estado atual do conhecimento sobre essa problemática inscreve-se no debate entre distintas tendências de análise dos anos de 1990 no campo da Sociologia da Educação. Alguns estudos enfatizam que os casos de longevidade escolar em meios populares podem ser explicados por uma forte mobilização escolar das famílias ${ }^{4}$ (LAURENS, 1992; ZÉROULOU, 1988). No entanto, se as pesquisas desses autores apontam que essa mobilização constitui condição necessária de sucesso escolar dos sujeitos que investigaram, outros estudos, que tomam o sucesso escolar em famílias populares como objeto de estudo, identificam, de forma predominante, uma 
ausência de práticas familiares que pudessem ser encampadas pela noção de mobilização escolar familiar (LAHIRE, 1997; LAACHER, 1990; 2005; VIANA, 2007).

Abre-se, então, um campo de investigação sobre outros fatores explicativos para o fenômeno em questão. Mostrar em que consiste e como se expressa a presença das famílias populares na escolarização dos filhos nos casos de longevidade escolar (LAACHER, 1990; 2005) constitui objeto fértil e necessário de estudos. É nesse contexto que abordo as práticas socializadoras familiares, pressupondo que essas práticas constituem um espaço privilegiado de constituição de disposições ${ }^{5}$ facilitadoras (ou dificultadoras) de sobrevida escolar nos meios populares. Foco nesse trabalho as disposições temporais.

\section{Relação com o tempo: breve revisão da literatura}

A análise da relação com o tempo, especificamente das disposições temporais, pode se inscrever em diversas dimensões da vida dos indivíduos e em diferentes universos de análise, como: o universo das temporalidades juvenis (SINGLY, 2000; LECCARDI, 2005); o da valorização da escola e das expectativas de futuro (COSTA; KOSLINSKY, 2006); o das consonâncias e dissonâncias entre disposições temporais familiares/individuais e escolares (THIN; MILLET, 2005; THIN, 2006); num sentido mais geral, o dos tipos de relação com o futuro (MERCURE, 1995; LECCARDI, 2005).

Essa revisão de literatura - centrada em Mercure (1995), Leccardi (2005), Singly (2000) e Charlot (1999) - recorta como eixo de análise a constituição de tipos de relação com o futuro.

O trabalho de Mercure (1995) sobre as temporalidades sociais, constituiu uma referência importante para fundamentar minhas hipóteses de pesquisa nesse campo. $\mathrm{O}$ autor defende a fecundidade heurística da utilização desse conceito, afirmando:

[...] numerosas contribuições científicas nos ensinam que o estudo das diversas maneiras de tomar consciência do tempo contribui muito para $a$ compreensão de certos fenômenos sociais, precisamente porque esquemas temporais, formas de simbolização do tempo, concepções e atitudes particulares em 
relação ao tempo, podem ter implicações mais ou menos diretas sobre os diversos modos de atividades. (MERCURE, 1995, p. 15; grifos meus).

Mercure (1995, p. 13) define "temporalidades sociais" como “[...] a realidade dos tempos vividos pelos grupos, isto é, a multiplicidade das condutas temporais e das representações do tempo ligadas à diversidade das situações sociais e dos modos de atividades no tempo.” Ou seja, como produtos de modos de socialização específicos. A ideia central que atravessa seu pensamento, nessa obra, é a de que a relação com o tempo é construída socialmente e só pode ser compreendida nessa perspectiva; para além, portanto, de uma concepção abstrata de relação com o tempo. Dentre as noções básicas trabalhadas por Mercure (1995, p. 20-21) adotei a de "horizonte temporal" como a mais pertinente para a compreensão do problema colocado. "O campo de projetos, de planificações, de previsões e de visões antecipadas, de expectativas e esperanças", constitui, segundo o autor, o cenário básico dessa noção. Com base em pesquisa empírica concluiu que, dentre as perspectivas dominantes de futuro, destacam-se a de conservação e a de conquista. A "perspectiva de conquista" caracterizase pelos seguintes traços:

- uma intenção de ultrapassar as condições do presente, aliada a um certo controle do mesmo;

- uma concepção de futuro mais como o produto das próprias ações do que como uma reação a pressões exteriores; mais como o que "deve ser" do que o que "pode advir" e do qual se deve proteger;

- a extensão dos horizontes temporais de futuro.

A título apenas de contraponto - uma vez que não constitui interesse desse trabalho -, os traços básicos da "perspectiva de conservação" são os seguintes:

- uma tendência a assegurar a manutenção das atuais condições de existência, ainda que o presente seja frágil e incerto; uma ausência relativa de controle do tempo presente, pelo menos ao nível das representações;

- o futuro concebido como um "advir" exterior, do qual é preciso se proteger, ou seja, uma atitude passiva diante de um futuro que "vem"; 
- horizontes temporais de futuro curtos, ou seja, “o atual está no centro do futuro" (MERCURE, 1995, p. 87-88).

Leccardi (2005) desenvolve uma reflexão sobre a relação com o tempo futuro ancorada nos processos contemporâneos de socialização dos jovens; considerando sua especificidade, em alguns aspectos sua análise se aproxima da de Mercure (1995). A reflexão da autora considera os dois temas que seguem. De um lado, os tipos de relação com o futuro, individual e coletivo, que predominam na modernidade, contextualizando-os historicamente numa "primeira modernidade" e numa "modernidade contemporânea". Para essa análise, a autora não distingue clivagens sociais, étnicas e de gênero, mas, de uma maneira mais universal, aponta a existência de seu impacto na individualização das biografias. De outro, a autora discute as tendências mais atuais de temporalização para os jovens.

Recorto, a seguir, alguns elementos dessa análise sobre os processos modernos e contemporâneos de socialização no contexto dos quais se produziram/produzem modos de se conceber e vivenciar o tempo. Ou seja, apresento alguns modelos de orientações temporais básicos que, segundo a autora, se sucederam no curso da "primeira modernidade" e da "modernidade contemporânea".

Tradicionalmente, nas sociedades ocidentais, na modernidade, a repressão dos impulsos hedonísticos estava na base dos processos modernos de socialização (MERCURE, 1995, p. 2). A preparação dos jovens para a vida adulta pressupunha um horizonte temporal estendido (capacidade de autocontrole, de disciplina no uso do tempo etc.) que pode conceder "diferimento das recompensas" para um tempo vindouro. A relação com o futuro apresenta(va), então, os traços que se seguem. Em primeiro lugar, se definia como balizamento para o agir individual e coletivo, constituindo-se norte para um projeto de vida e de uma “definição de si”; em segundo lugar, tornando-se o centro das ações dos homens e dependendo inteiramente da ação dos sujeitos, caracterizava-se como controlável e planificável predominando uma concepção laica; finalmente, o futuro concebido como espaço de construção de "um projeto de vida", a perspectiva biográfica, que pressupõe um horizonte temporal distendido. Nesse contexto, emerge a possibilidade de "autonomia do indivíduo", uma vez que o futuro se coloca à sua disposição como espaço de experimentação (MERCURE, 1995, p. 5). Um projeto coletivo - vinculado à liberdade, à democracia, à igualdade, ao 
bem-estar econômico - aparece como condição básica e como horizonte dos projetos individuais (MERCURE, 1995, p. 7).

$\mathrm{Na}$ contemporaneidade (a partir de fins século XX) um componente de incerteza e os imediatismos, assim como as "vivências contingentes", tendem a dominar o cenário. Torna-se pouco sensato pensar/investir em projetos de longo prazo e, mais ainda, adiar satisfações. Produz-se, assim, um "horizonte temporal comprimido", a vida se estruturando mais em torno do presente. Surgem novas formas de "temporalização", uma delas, básica, sendo a de "pulverização da experiência de tempo". Não há um continuum temporal; "os intervalos de tempo dispõem-se um ao lado do outro e não em uma progressão lógica". ${ }^{6}$ Além disso, o horizonte de futuro passa a ser construído no contexto de riscos. O tempo presente passa a ser o referente central para o indivíduo singular e coletivo.

Pesquisa de Leccardi (2005), ${ }^{7}$ problematizando a relação dos jovens com o tempo, aponta alguns dados interessantes. Um deles diz respeito à identificação de uma concepção de tempo como "presente estendido", assim definido:

[...] não mais o futuro, mas o presente mais próximo - o lapso temporal suficientemente breve para não fugir ao domínio humano e social, mas também suficientemente amplo para consentir alguma forma de projeção para além no tempo. (LECCARDI, 2005, p. 7).

Esse tempo "fragmentado em episódios" tende a apagar a ideia de projeto e, consequentemente, surgem novas formas de construções biográficas. A figura do "nômade" é utilizada por Melucci (1997) como metáfora das biografias contemporâneas, caracterizadas como tendência à experimentação, à provisoriedade, diferentemente de biografias construídas em torno de metas.

Hoje, segundo Leccardi (2005), um percurso previsível para o ingresso na vida adulta constitui exceção. Identifica-se uma ausência de etapas tradicionais, previsíveis, normativas, como: conclusão dos estudos, inserção no trabalho, independência de moradia, casamento, filhos. Assiste-se a uma "desinstitucionalização" da vida, ou seja, as instituições estão presentes nas biografias, mas deixaram de ser base da "continuidade 
biográfica". Uma ilustração desse fenômeno pode ser vista em relação aos estudos universitários: os jovens podem "interrompê-los, retomá-los e depois concluí-los, sem que a aquisição de credenciais educacionais superiores represente uma verdadeira 'reviravolta' no plano biográfico." (LECCARDI, 2005, p. 9). Resultados de pesquisa mostram também que, apesar do quadro descrito, percebe-se diferenciações nas atitudes de autodeterminação nas escolhas e utilização de estratégias pelos sujeitos, conforme o impacto das clivagens sociais, étnicas e de gênero. Assim, mesmo que o futuro se configure como incerto, inseguro, contingente, há casos de não absolutização do presente imediato e onde se identifica uma 'habilidade de manter uma direção ou trajetória, a despeito da impossibilidade de prever seu destino final.” (LECCARDI, 2005, p. 9). Alguns jovens - uma parcela minoritária -, pertencentes aos grupos culturalmente dominantes, podem lidar positivamente com a imprevisibilidade. Esse controle sobre o tempo significa, antes de tudo, uma "vontade" de atingir objetivos que pressupõe a posse de determinados recursos culturais, sociais e econômicos (LECCARDI, 2005, p. 9). A maioria dos jovens, tendo um futuro fora de controle e um "presente estendido" como referência principal - um presente "sem fascínio" -, elabora projetos de curto ou curtíssimo prazo. Esses projetos curtos constituem uma terceira via "entre a capacidade especial de gestão da complexidade [...] e a referência exclusiva ao presente daqueles que não conseguem construir reações adequadas diante do crescimento da indeterminação do futuro." (LECCARDI, 2005, p. 10).

Embora Singly (2000) não tome como objeto específico de discussão a relação com o tempo, sua problematização das formas de se pensar a juventude na contemporaneidade faz fronteiras com e complementa a análise precedente. Considerando o processo de individualização como o modo característico de constituição do indivíduo moderno, esse autor coloca no centro de sua reflexão a "dissociação" inscrita no processo de socialização do jovem contemporâneo. Dissociação entre duas dimensões essenciais: a autonomia e a independência (econômica). Singly (2000) chega a definir juventude como uma faixa de idade que se caracteriza por essa dissociação.

A ênfase colocada nesse fenômeno leva-o a tentar compreender as suas origens e efeitos. Assim, as origens da dissociação entre autonomia e independência estariam, por um lado, na valorização contemporânea 
atribuída à individualização do sujeito (condição de expressão de si) e, por outro, no fenômeno do prolongamento da escolaridade. Este último traria um adiamento da entrada no mercado de trabalho e, portanto, do acesso à independência econômica. Paradoxalmente, esse prolongamento dos estudos traria efeitos perversos para aqueles que não conseguem empreender uma escolarização completa, estando excluídos do mercado de trabalho mais qualificado. Como consequência marcante da dissociação em pauta é apontada a possibilidade, para os jovens, de uma "autonomia sem independência econômica"; noutros termos, de uma autonomia relativa. As sociedades contemporâneas - centradas sobre o indivíduo colocariam para os jovens o dilema dessa dissociação. $\mathrm{O}$ autor argumenta, ainda, que as condições de possibilidade de superação dessa dissociação são desigualmente repartidas. No entanto, destaco esse aspecto, Singly (2000) assinala também que os processos socializadores familiares entram em cena na medida em que "há famílias, hoje, que ensinam o filho a ser autônomo, sem, no entanto, esse último se beneficiar de uma independência econômica em relação aos pais, vivendo sob o regime da dissociação."

Uma das possibilidades de encontrar pontos de articulação nas análises de Singly (2000) e de Leccardi (2005) está, a meu ver, no contexto de incerteza e de "vivências contingentes" que a dissociação entre autonomia e independência econômica pode implicar. Os projetos de longo prazo encontrariam dificuldades de serem formulados. A vida se estruturaria mais em torno do presente.

Charlot (1999), por sua vez, estudando jovens de meios populares, oferece contribuições importantes para a discussão que aqui se trava. ${ }^{8}$ Para alguns dos jovens investigados existe um "curso normal do tempo", uma rotina da vida, uma sucessão cronológica do tempo: "se é criança, tenta-se aproveitar a juventude e, ao mesmo tempo, vencer nos estudos; obtém-se diplomas, encontra-se um trabalho; casa-se, tem-se filhos." (CHARLOT, 1999 , p. 56). Esses jovens inscrevem seus projetos no tempo longo de uma "vida normal", que inclui a geração dos próprios filhos. No entanto, essa "vida normal" não está assegurada para jovens oriundos dos meios populares. Para eles, o curso da construção da vida, no tempo, pode ser perturbado e, muitas vezes, interrompido, para melhor ou para pior; a vida pode "balançar" em função de um episódio - ligado, seja à família, ao trabalho, à escola, à religião, à droga -, a partir do qual há um "antes" 
e um "depois". O tempo da vida pode ser atravessado por rupturas que desorganizam o curso normal da vida.

Alguns desses jovens vivenciam esse fenômeno com algum nível de fatalismo. Outros, ao contrário, pensam que é preciso "provocar" as coisas, porque nada, jamais, vem sem esforço. Esses últimos, apesar de se inscreverem no tempo longo da vida, mantêm uma relação "tática" com o tempo - não estratégica, como as camadas médias -, no sentido da planificação da vida, por duas razões. Como referido, porque estão expostos a instabilidades ameaçadoras que podem provocar rupturas no curso da vida; o desemprego, por exemplo: “[...] o desempregado não dispõe de tempo, ele é arremessado para fora dele, para fora do curso normal das coisas; ou, noutros termos, ele é mergulhado num tempo que não flui mais." (CHARLOT, 1999, p. 63). Ademais, porque esses jovens elaboram projetos muito simples que, numa perspectiva das camadas médias, dos professores etc., não seriam nem considerados "projetos". O que eles almejam é "ter um trabalho, um apartamento, um carro, férias, [...] isto é, tudo o que as classes médias vivem como uma evidência, de tal forma que não chega a constituir para elas um projeto." (CHARLOT, 1999, p. 62).

\section{Disposições temporais de futuro distendido: alguns dados empíricos}

O diálogo da teoria com a empiria que estabeleço provém de duas fontes: de uma pesquisa mais recente, referida, da qual extraio fragmentos da trajetória escolar e familiar de um dos casos, o de Regina ${ }^{9}$, assim como desenvolvo uma breve reflexão transversal extraída de dados dos sete casos estudados; de dois casos de uma pesquisa anterior, dos quais discuto elementos de suas trajetórias (VIANA, 2007).

Regina é caçula e única mulher numa fratria de cinco irmãos, a única que chegou ao ensino superior. Sua mãe ficara viúva com os filhos adolescentes, tendo que assumir sozinha a manutenção e formação dos mesmos, destacando-se como uma figura forte em suas práticas educativas. Ela acreditava que era possível superar as condições materiais adversas de vida em que viviam - "[...] tinha horror da pobreza" afirma Regina - e que o caminho para a realização de tal objetivo era escolarizar os filhos. Essa crença aparecia num reiterado discurso sobre essa possibilidade. Se expressa, aí, uma 
disposição à emancipação das condições materiais e culturais de existência e, à medida que os filhos iam conquistando melhores condições de vida por meio da escolarização, ampliava sua crença nessa alternativa. A propósito de um dos filhos que se formou em contabilidade (nível técnico) e que montou o próprio escritório, por exemplo, ela declara: "se vocêfor contador [que implica em escolarização], você vai ser o dono do próprio escritório". Os outros filhos, embora tivessem concluído "apenas" a 8 a série do Ensino Fundamental, conseguiram se afirmar em ocupação não manual, "de escritório”.

Num Colégio Militar de Belo Horizonte ${ }^{10}$, por onde passaram Regina e todos os seus irmãos, Regina tivera que vencer pesadas barreiras materiais e culturais. "[...] se era difícil, a gente tinha que arrumar jeito". As buscas na biblioteca pública, que era longe de casa e para onde iam a pé, por exemplo. Ela vivera na escola a experiência de um confronto com o universo material e social de sua família. Embora adaptada na escola, havia a vivência de um distanciamento, ocultado:

Não levava colega minha na minha casa; eu só estudava com filhas de coronel, de major; mais pobre lá era o sargento e o meu irmão era um simples soldado; minha casa não tinha nada pra oferecer; ai era aquela bistória que a minha mãe sempre falava, 'não passa atestado de pobreza' (REGINA).

Nesse contexto ressalto a importância atribuída pela mãe de Regina ao uso do uniforme escolar, que homogeneizaria todos os alunos pela aparência e ocultaria a pobreza. Daí o seu cuidado para que ela e seus irmãos o portassem sempre "impecável". "Aparentemente, eu não era tão pobre; [mas] eu, internamente, sabia que era diferente". Regina aprendera com a mãe a não exibir traços de pobreza, para não se expor à humilhação, ao ridículo.

Para a mãe de Regina, havia mais do que uma crença na possibilidade de um futuro melhor para os filhos; havia, sim, uma "convicção". Ela acreditava, ainda, que essa mobilidade social se efetivaria num tempo longo, o de gerações: "a gente tem que fazer pro filho, pro filho fazer mais pro filho dele, pro filho dele ser mais do que ele [...] porque assim a gente vai melhorando de vida". Interiorizando essa disposição temporal de aposta num futuro melhor com base nas próprias ações, Regina declara, a propósito do momento de sua entrada na Universidade: "[...] parece que fica lá no seu inconsciente que você vai conseguir algo, se você prosseguir [...]”. Fora construída entre os membros 
dessa família uma disposição ascética em relação à vida e, particularmente, em relação à escola, tendo em vista o que ela pode oferecer em termos de superação das condições adversas de vida.

Considerando o conjunto dos sete casos estudados da pesquisa mais recente, concluo que práticas familiares favorecedoras da constituição de disposições temporais de futuro alargado foram uma marca forte de todos eles. Esse horizonte temporal distendido teve como pano de fundo a crença na possibilidade de uma vida melhor para os filhos, expressa no discurso, mas também em indicadores objetivos como:

- na luta para escolarizar os filhos, embora, na maioria dos casos, tendo o ensino médio como o horizonte final;

- na prioridade para os estudos em detrimento do trabalho;

- em investimentos sistemáticos de superação das turbulências materiais ao longo da história da família;

- na interdição ao ócio, ligada ao temor da decadência moral dos filhos;

- no cuidado com a aparência física dos mesmos, sobretudo na escola, apoiado no temor de "parecer" pobre.

As lutas das famílias investigadas para sobreviver às turbulências materiais estiveram intimamente ligadas, embora não exclusivamente, com outra luta, a de escolarizar os filhos. Essas lutas, por sua vez, se inscreviam - e, segundo meu entendimento, podiam ser explicadas pela -, na existência de um horizonte temporal de futuro distendido entre os membros da família, isto é, pela crença de que "melhorar de/a vida" era possivel.

De minha pesquisa anterior (VIANA, 2007) selecionei fragmentos das histórias escolares de André e de Júlia, tomadas numa perspectiva verticalizada sob a forma de casos singulares. Considero-as exemplares de uma relação com o tempo futuro que é facilitadora de sobrevida escolar. ${ }^{11}$

André, o mais velho de uma fratria de oito irmãos, tinha 26 anos no momento da entrevista, quando concluía o $2^{\circ}$ período de seu curso de Economia na Pontifícia Universidade Católica de Minas Gerais - PUC-MG, apoiado por uma bolsa de estudo.

Uma das dimensões mais marcantes da trajetória escolar desse jovem é sua "disposição de conquista" diante do futuro. "Ser possível” e "num 
tempo possível" foram atitudes fortemente mobilizadoras de energias subjetivas e materiais para seu empreendimento escolar. Um dos momentos da entrevista com esse jovem foi particularmente expressivo dessa atitude básica diante do tempo futuro; indagamos sobre como explicaria diferenças entre ele e colegas seus que, com idade e condições sociais semelhantes, haviam abandonado a escola há muito tempo. Ultrapassando o nível do simples relato de fatos, muitas vezes hesitante na formulação de sua fala, mostrou-se extremamente engajado na problemática proposta, tentando, ao mesmo tempo em que nos respondia, compreender-se e explicar-se. Ainda que extensa, transcrevemos sua reflexão:

O que eu tenho notado é que parece, assim [...] pessoas que convivem comigo atualmente e que já conviveram também $[. .$. parece que o que eles têm na cabeça hoje é aquela coisa do imediato, sabe? Eles querem estar aqui, agora [...] eles são muito imediatistas; é o que está acontecendo agora. Eles não têm projeto nenhum para o futuro! Eles são bem o presente mesmo, e tal; viver o presente do jeito que ele tiver acontecendo e o futuro, quando ele chegar, a gente vê o que far, entendeu? O futuro como alguma coisa que tem que construir, entendeu? Eu não consigo imaginar isso, não. Eles têm a mesma capacidade que eu! Não consigo compreenderporque elespensam dessa forma! [...] A impressão que eu tenho, é que eles acham que têm uma adolescência eterna! (grifos meus).

André comenta que alguns de seus colegas das camadas populares, numa espécie de lamento sobre a própria sorte, tecem frequentes comentários acerca da situação privilegiada de jovens de classe média, dizendo que estes últimos estariam tranquilos "porque têm herança" da família. Só que, questiona André, aqueles colegas que, como ele, não têm herança, consideram, diferentemente, que "nada têm que construir". "Eu tenho que construir minha própria herança", afirma ele.

Entendemos que esse jovem expressa uma concepção de que "construir a própria herança" seja possivel. André entende, portanto, que o acesso à Universidade é possivel para ele e para outros jovens das camadas populares. Só que essa concepção de mundo tem que se materializar enquanto projeto, enquanto algo que deve ser conquistado! Ele acredita que 
as condições adversas do presente podem ser superadas e, nesse sentido, constrói e atualiza o que Mercure (1995) denomina de "plano de vida". Ou seja, sua vida é norteada pelo que deseja para o seu futuro: "eu sei o que quero pra minha vida futura".

Uma outra condição facilitadora da sobrevivência escolar de André, explicada no campo das disposições temporais, foi a de se adaptar ao tempo que lhe era/foi possível para construir seu caminhar na direção pretendida com persistência e fôlego. Sua trajetória é rica em exemplos dessa firmeza em não se desviar da rota: a forma como, estrategicamente, viveu e superou suas reprovações, assim como o período difícil de adaptação ao universo cultural e social do ensino superior e a premente e constante necessidade de conciliar trabalho com estudo. Essa tenacidade se mostra particularmente em relação a uma de suas reprovações, quando teve de se confrontar com injunções complicadas de vida. Nesse contexto, algumas expressões como "vou dar um tempo" ou "eu não parei” constituem verdadeiras palavras de ordem, norteadoras de sua relação com o futuro e com a vida.

A trajetória escolar de Júlia, particularmente atípica, representa uma outra ilustração rica do que defendo nesse trabalho - a de que determinadas disposições temporais podem representar um elemento explicativo, dentre outros, de destinos escolares prolongados até o ensino superior em meios populares. Ela nasceu e viveu até os 32 anos "na roça", quando entrou para a Universidade. No momento da entrevista tinha 38 anos. Sua experiência de frequentar a escola regular foi muito reduzida. Não passou pelo "Jardim da Infância"; cursou as três primeiras séries do Ensino Fundamental num estabelecimento escolar municipal rural e, daí, deu um "grande salto" para a Universidade. Toda a sua formação, a partir da 4ª́rie "primária", incluindo o Ensino Médio, foi realizada pela via do ensino supletivo, assim nomeado à época.

A “escola primária” que Júlia frequentou fica num pequeno povoado, a $4 \mathrm{~km}$ de onde morava, povoado que pertence a uma cidade da região metropolitana de Belo Horizonte. Ela ia à escola e voltava a pé. No caminho atravessava um pequeno rio sem ponte que, na época das chuvas, impossibilitava o acesso à escola. Quando concluiu a $3^{\mathrm{a}}$ série, teve de interromper os estudos por falta da oferta de escola. Para continuar a estudar teria que mudar para a cidade mais próxima e isto era impensável naquele momento por absoluta falta de condições, sobretudo econômicas. 
Júlia só foi retomar os estudos aos 20 anos, motivada por um convite para ser monitora na escola rural onde estudou. A diretora dessa escola "obrigou-a" a cursar imediatamente a $4^{a}$ série para assumir essa função. Não era objetivo seu fazer a $4^{a}$ série naquele momento, mas organizar a vida para sair da roça e só mais tarde continuar os estudos. "Sair da roça" tinha, para Júlia, um duplo sentido: o de se deslocar fisicamente para a cidade, mas também (e sobretudo?) "sair" cultural e socialmente daquele lugar. Por força das circunstâncias, aceitou cursar a $4^{\mathrm{a}}$ série naquele momento, o que fez no Movimento Brasileiro de Alfabetização (MOBRAL).

A partir dos 27 anos Júlia retomou seus estudos de uma forma mais sistemática, nesse momento com o objetivo de diplomar-se, porque, na verdade, ela estivera, até então, sempre estudando, mas "informalmente". Essa nova fase compreende o período em que desenvolveu, por correspondência com o Instituto Universal Brasileiro, com sede em São Paulo, as últimas séries do Ensino Fundamental (de $5^{\mathrm{a}}$ à $8^{\mathrm{a}}$ série) e todo o Ensino Médio. Para subsidiar esse período de estudo, conseguiu duas bolsas de estudo; uma que cobriu a parte final do Ensino Fundamental e outra, o Ensino Médio. A primeira bolsa foi obtida por meio de um programa sertanejo de rádio. A segunda bolsa veio do próprio Instituto Universal Brasileiro, instituição que lhe conferiu os diplomas de Ensino Fundamental e Médio. Foi de um ano esse tempo de estudos via supletivo.

Assim que conseguiu o diploma de nível médio, se inscreveu no vestibular da UFMG, sem frequentar cursinho. O primeiro vestibular que tentou foi para o curso de Direito, no ano de 1990, quando foi reprovada na $2^{\text {a }}$ etapa. No ano seguinte tentou novamente, mas desta vez para o Curso de Geografia. De um vestibular para o outro, se preparou também sem frequentar cursinho, "sempre atualizando pra tentar vestibular de novo", afirma. Logo que se viu amparada por uma bolsa da Fundação Mendes Pimentel (FUMP) da Universidade Federal de Minas Gerais (UFMG), deixou a casa dos pais.

A trajetória escolar de Júlia me parece exemplar para discutir disposições temporais em relação ao futuro. Essa trajetória foi construída num "tempo próprio", entendido como o "tempo do possível”, num duplo sentido. O primeiro, no sentido de uma "aceitação" de que ela só poderia chegar à Universidade trabalhando dentro de suas condições objetivas de vida. Estamos qualificando essa "aceitação" de ativa e estratégica e 
colocando a hipótese de que ela expressa um tipo particular de disposição em relação ao tempo que pode ter sido um importante trunfo facilitador do seu êxito escolar.

O fato de morar na roça, de viver numa família que, além de não investir esforços em sua escolarização, também, do ponto de vista simbólico, "não autoriza" o seu movimento de emancipação, de não dispor de recursos econômicos, configuram uma situação que inscreve Júlia na necessidade de construir sua trajetória até à Universidade num tempo não linear, mas acidentado. Ela abriu seus caminhos "a picareta" e, portanto, num "outro" tempo. Não podia ter pressa; ou as coisas aconteceriam nesse tempo ou não aconteceriam. Antes dos 32 anos não era possível para ela chegar à Universidade e antes dos 20 fazer a $4^{a}$ série do Ensino Fundamental.

Um outro sentido para o que estamos chamando de "tempo possível", intimamente ligado ao anterior, é o de serpossivel; o de uma representação de futuro fundada principalmente numa atitude de "conquista" e, portanto, de horizonte temporal ampliado. Tudo se passa como se ela mantivesse consigo mesma o seguinte diálogo interno: “daqui a ' $\mathrm{x}$ ' anos, mas vou chegar lá”. Toda a história escolar de Júlia indica uma vontade obstinada de não reproduzir certas condições de sua família, principalmente a de "ser da roça", desprovida dos conhecimentos escolares que possibilitam um outro tipo de inserção no mundo. E essa vontade se materializou em intervenções e investimentos pessoais muito concretos, indicadores de que ela concebia o futuro como resultado das próprias ações e não como algo que vem como fatalidade do exterior (MERCURE, 1995).

A disposição dominante em relação ao futuro identificada nos casos de André e Júlia - constituindo a tônica dos outros casos que fundamentam esse trabalho (VIANA, 2007, 2006) - foi a de conquista. ${ }^{12}$

\section{Consideração final}

Concluo esse trabalho retomando e defendendo a tese da relação entre práticas socializadoras diferenciadas no interior das famílias populares e a constituição de disposições temporais diferenciadas que podem se constituir em condições facilitadoras de longevidade escolar nesses meios. Assim, se onde as condições de vida são mais precárias prevalece uma disposição dominante de reprodução dessas condições e se, ao contrário, condições 
de vida que tornam o presente mais estável favorecem a elaboração de disposições e condutas de conquista (MERCURE, 1995), não há, no entanto, um determinismo absoluto que dotaria os sujeitos das camadas populares com disposições conservadoras ou ausência de planos de vida.

\section{Notas}

1 Para preservar o anonimato dos entrevistados os nomes utilizados no trabalho são fictícios.

2 Este trabalho constitui uma versão ligeiramente modificada do que foi apresentado no XIII Congresso Brasileiro de Sociologia - SBS, realizado na Universidade Federal de Pernambuco - UFPE, Recife, de 29 de maio a $1^{\circ}$ de junho de 2007 .

3 Pesquisa que obteve financiamento da FAPEMIG e do CNPq. Incluo nesse trabalho alguns elementos das trajetórias de dois casos de uma pesquisa anterior (VIANA, 2007), resultados de uma investigação realizada no meu processo de doutoramento (FaE/UFMG), defendido em dezembro de 1998.

4 “Mobilização escolar" entendida como atitudes e intervenções práticas das famílias voltadas para o rendimento escolar dos filhos.

5 Lahire (2004, p. 74) define "disposição" como o produto incorporado de uma socialização, de um "passado que se sedimentou, de alguma forma, e se converteu em maneiras mais ou menos duráveis de ver, sentir e agir, isto é, em características disposicionais: propensões, inclinações, hábitos, tendências, persistentes maneiras de ser".

6 Bauman, Z. La società dell incertezza. Bologna: Il Mulino, 2000, apud Leccardi (2005).

7 Referência a uma pesquisa sobre a condição juvenil contemporânea, realizada na Itália, nos anos de 1980, que teve a participação da autora: A Cavalli, Il tempo del giovani, Bologna: Il Mulino, 1985, apud Leccardi, 2005.

8 Pesquisa que se inscreve num programa mais amplo da equipe ESCOL - Éducation, Socialisation e Collectivités Locales, anos de 1990, 
Université Paris 8, Saint Denis. Charlot (1999, p. 47), analisando dados empíricos de investigação sobre a "relação com o saber" de jovens de liceus populares na França, defende que a questão do tempo é uma às quais se deve atribuir grande atenção, quando se analisa essa relação.

9 Os dados dessa pesquisa - sobre disposições temporais facilitadoras de longevidade escolar constituídas no contexto de práticas socializadoras de famílias populares - foram descritos sob a forma de casos singulares no Relatório de Pesquisa (VIANA, 2006).

10 Vale destacar, sem entrar em descrição de detalhes, a luta insana e persistente dessa mãe para conseguir vaga nesse estabelecimento de ensino para todos os filhos, assim como para mantê-los lá.

11 Nessa pesquisa, ao tratar das disposições temporais de futuro, não foquei, como em pesquisa recente, as práticas socializadoras familiares que as teriam engendrado.

12 Disposição que é estatisticamente atípica para os meios populares, segundo Mercure (1995). Ao estabelecer uma relação entre posição social e representações de futuro, num universo de 41 sujeitos econômica e culturalmente mais desfavorecidos, esse autor identifica 9,7\% com perspectiva de "conquista" em relação ao futuro e, nessa mesma perspectiva, $66,7 \%$ entre os 24 sujeitos de nível socioeconômico superior. Na perspectiva de "conservação" diante do futuro, ao contrário, estariam $61 \%$ das camadas inferiores.

\section{Referências}

CHARLOT, B. Qu'est-ce que est important pour eux? Qu'est-ce qu'ils attendent? le rapport au temps. In: LE RAPPORT au savoir en milieu populaire: une recherche dans les lycées profissionnels de banlieue. Paris: Anthropos, 1999. p. 47-63.

COSTA, Márcio; KOSLINSKY, Mariane Campelo. Entre o mérito e a sorte: escola, presente e futuro na visão de estudantes do ensino fundamental do Rio de Janeiro. Revista Brasileira de Educação, São Paulo, v. 11, n. 31, jan./abr. 2006. p. 133-154. 
LAACHER, Smaïn. L'école et ses miracles: notes sur les déterminants sociaux des trajectoires scolaires des enfants de familles immigrées. Politix, Paris, n. 12, p. 25-37, 1990.

. L'institution scolaire et ses miracles. Paris: La Dispute, 2005.

LAHIRE, Bernard. Sucesso escolar nos meios populares: as razões do improvável. Tradução de Ramon Américo Vasques e Sonia Goldefer. São Paulo: Ática, 1997.

. Retratos sociológicos: disposições e variações individuais. Porto Alegre: Artmed, 2004.

LAURENS, Jean-Paul. 1 sur 500: la réussite scolaire en milieu populaire. Tolouse: Presses Universitaires du Mirail, 1992.

LECCARDI, Carmen. Para um novo significado do futuro: mudança social, jovens e tempo. Tempo social, São Paulo, v. 17, n. 2, p. 35-57, 2005. Disponível em: <http:/www.scielo.br>. Acesso em: 3 out. 2006.

MELUCCI, Alberto. Juventude, tempo e movimentos sociais. Revista Brasileira de Educação, São Paulo, n. 5/6, p. 5-14, 1997.

MERCURE, Daniel. Les temporalités sociales. Paris: Éditions L'Harmattan, 1995.

SINGLY, François. Penser autrement la jeunesse: lien social et politiques. RIAC, Paris, n. 43, p. 9-21, 2000.

THIN, Daniel. Para uma análise das relações entre famílias populares e escola: confrontação entre lógicas socializadoras. Revista Brasileira de Educação, São Paulo, v. 11, n. 32, p. 211-225, 2006.

THIN, Daniel; MILLET, Matias. Des postures contraires aux logiques scolaires. In: . Ruptures scolaires: l'école à l'épreuve de la question sociale. Paris: PUF, 2005. p. 137-155.

VIANA, Maria José Braga. Formas específicas de presença das famílias de camadas populares na escolarização dos filhos: casos de longevidade escolar. Belo Horizonte: FaE/UFMG, 2006. Relatório de Pesquisa.

. Longevidade escolar em famílias populares: algumas condições de possibilidade. Goiânia: Ed. da Universidade Católica de Goiás, 2007. 
VIANA, Maria José Braga. As práticas socializadoras familiares como locus de disposições facilitadoras de longevidade escolar em meios populares. Educação \& Sociedade, Campinas, n, 90, p. 107-125, 2005. ZÉROULOU, Zaihia. La réussite scolaire des enfants d'immigrés: l'apport d'une approche en termes de mobilisation. Revue Française de Sociologie, Paris, v. 29, n. 3, p. 447-40, 1988. 


\section{Temporal dispositions of the future and school longevity in low income families}

\section{Abstract:}

This paper presents the results of two studies about a common issue: the conditions that allow the statistically improbable phenomenon of school longevity in low income families. More specifically, it seeks to identify in the socializing practices of these families a space for constitution of measures that support permanence in school among their children. I maintain that this would be one of the ways by which low income families can be present in the prolonged schooling of their children. Among the types of dispositions investigated I highlight temporal ones. In a recent study I studied seven cases of students in the College of Pedagogy at FaE/UFMG in 2002 and 2003, through interviews; these subjects were selected from a group of 120 hand written school biographies. Although it focuses on data from interviews, the analysis presented here also considers elements of these autobiographies, as well as the trajectories of two cases from a previous study. A general conclusion of these studies is that these families have an expanded perspective of the future - a position that is not typical among low income groups - expressed above all in the

\section{Disposiciones temporales de futuro y de longevidad escolar en familias populares}

\section{Resumen:}

En este trabajo se describen resultados de dos investigaciones que abordan una problemática de fondo común: las condiciones que posibilitan el fenómeno, estadísticamente improbable, de la longevidad escolar en las clases populares. Más específicamente, procuro identificar en las prácticas socializadoras de las familias populares un espacio de constitución de las disposiciones facilitadoras de longevidad escolar en esos medios. Defiendo que esta sería una de las formas por medio de la cuales las familias populares estarían presentes en la escolarización prolongada de los hijos. Dentro de los tipos de disposiciones investigadas en este trabajo se destaca, el analisis que, aqui desarrollamos som los elementos de esas disposiciones temporales. En otra investigación reciente, estudié siete casos de estudiantes del Curso de Pedagogía del FaE/ de la Universidad Federal de Minas Gerais (UFMG), Brasil, de los años de 2002 y 2003, mediante entrevistas, y esos sujetos fueron seleccionados en el interior de un corpus de 120 biografías escolares producidas de forma escrita. Aunque focalizamos los datos de las entrevistas, el análisis que aqui desarrollamos son los elementos de esas autobiografías, como también, la trayectoria de dos casos de una pesquisa anterior. Una conclusión más 
possibility for a better life for their children via schooling.

Key words: School and home. Schooling. Family. general de este estudio es que existe, en esas familias, un horizonte de futuro distendido - disposición que es atípica en los medios populares - manifiesto especialmente, en la posibilidad de una vida mejor para los hijos por medio de la escuela.

Palabras-clave: Hogar y escuela. Escolaridad. Familia.

\section{Maria José Braga Viana}

Universidade Federal de Minas Gerais, Faculdade de Educação, Departamento de Ciências Aplicadas à Educação Av. Antonio Carlos, 6627 - Pampulha, Belo Horizonte-MG CEP: 31270-901

E-mail:mj.braga@terra.com.bre mjbraga@fae.ufmg.br

Recebido em: $11 / 3 / 2008$

Aprovado em: 22/5/2008 